\title{
Enhanced Tolerance of Chinese Cabbage Seedlings Mediated by Bacillus aryabhattai H26-2 and B. siamensis H30-3 against High Temperature Stress and Fungal Infections
}

\author{
Young Hee Lee ${ }^{1}$, Su Jeong Jang ${ }^{1}$, Joon-Hee Han ${ }^{5}$, Jin Su Bae ${ }^{1}$, Hyunsuk Shin ${ }^{1}$, Hee Jin Park ${ }^{2}$, \\ Mee Kyung Sang ${ }^{3}$, Song Hee Han ${ }^{4}$, Kyoung Su Kim ${ }^{5}$, Sang-Wook Han ${ }^{6}$, and Jeum Kyu Hong (i) 1* \\ ${ }^{I}$ Department of Horticultural Science, Gyeongnam National University of Science and Technology (GNTech), 33 \\ Dongjin-ro, Jinju 52725, Korea \\ ${ }^{2}$ Institute of Glocal Disease Control, Konkuk University, Seoul 05029, Korea \\ ${ }^{3}$ National Institute of Agricultural Science, Rural Development Administration, Wanju 55365, Korea \\ ${ }^{4}$ Hyunnong Co., Ltd, Gokseong-gun 57509, Korea \\ ${ }^{5}$ Division of Bioresource Sciences, Kangwon National University, Chuncheon 24341, Korea \\ ${ }^{6}$ Department of Integrative Plant Science, Chung-Ang University, Anseong 17546, Korea
}

(Received on July 18, 2018; Revised on August 28, 2018; Accepted on September 10, 2018)

Two rhizobacteria Bacillus aryabhattai $\mathrm{H26}-2$ and $B$. siamensis $\mathrm{H30-3}$ were evaluated whether they are involved in stress tolerance against drought and high temperature as well as fungal infections in Chinese cabbage plants. Chinese cabbage seedlings cv. Ryeokgwang (spring cultivar) has shown better growth compared to cv. Buram-3-ho (autumn cultivar) under high temperature conditions in a greenhouse, whilst there was no difference in drought stress tolerance of the two cultivars. In vitro growth of $B$. aryabhattai $\mathbf{H 2 6 - 2}$ and $B$. siamensis $\mathrm{H30-3}$ were differentially regulated under PEG 6000-induced drought stress at different growing temperatures $\left(30,40\right.$ and $\left.50^{\circ} \mathrm{C}\right)$. Pretreatment with $B$. aryabhattai $\mathrm{H26-2}$ and $B$. siamensis $\mathrm{H30-3}$ enhanced the tolerance of Chinese cabbage seedlings to high temperature, but not to drought stress. It turns out that only B. siamensis H30-3 showed in vitro antifungal activities and in planta crop protection against two fungal

\footnotetext{
*Corresponding author.

Phone) +82-55-751-3251, FAX) +82-55-751-3257

E-mail) jkhong@gntech.ac.kr

ORCID

Jeum Kyu Hong

http://orcid.org/0000-0002-9161-511X

(c) This is an Open Access article distributed under the terms of the Creative Commons Attribution Non-Commercial License (http:// creativecommons.org/licenses/by-nc/4.0) which permits unrestricted noncommercial use, distribution, and reproduction in any medium, provided the original work is properly cited.
}

Articles can be freely viewed online at www.ppjonline.org. pathogens Alternaria brassicicola and Colletotrichum higginsianum causing black spots and anthracnose on Chinese cabbage plants cv. Ryeokgwang, respectively. B. siamensis $\mathrm{H30-3}$ brings several genes involved in production of cyclic lipopeptides in its genome and secreted hydrolytic enzymes like chitinase, protease and cellulase. B. siamensis H30-3 was found to produce siderophore, a high affinity iron-chelating compound. Expressions of BrChil and BrGST1 genes were up-regulated in Chinese cabbage leaves by $B$. siamensis H30-3. These findings suggest that integration of $B$. aryabhattai $\mathbf{H 2 6 - 2}$ and $B$. siamensis $\mathrm{H30-3}$ in Chinese cabbage production system may increase productivity through improved plant growth under high temperature and crop protection against fungal pathogens.

Keywords : antifungal, Bacillus, biocontrol, Chinese cabbage, high temperature stress

Handling Associate Editor : Ryu, Choong-Min

Chinese cabbage production has been severely limited by drought and high temperature. Soil water deficit caused growth retardation of Chinese cabbage plants with reduced leaf area and lower fresh weight (Lee et al., 2015). Higher temperature increased the early growth of Chinese cabbage seedling but delayed the plant growth at the heading stage (Oh et al., 2014). Especially high temperature at daytime 
during the reproductive growth stage resulted in increased seed number per pod but significantly declined seed weight of Chinese cabbage plants (Angadi et al., 2000). To cope with drought and high temperature stresses for a sustainable Chinese cabbage production, a few eco-friendly approaches have been suggested. Germination of Chinese cabbage seeds primed with water, $\mathrm{KNO}_{3}$ and urea was less arrested under polyethylene glycol 6000 (PEG 6000)-mediated drought stress (Yan, 2015). Co-cultivation of Chinese cabbage plants with a root colonizing endophytic fungus Piriformospora indica attenuated the oxidative stress damage by PEG 4000-mediated drought (Sun et al., 2010). Since two heat-tolerant $F_{1}$ hybrids of Chinese cabbage were introduced, no appropriate cultural method was suggested for high temperature stress (Yang et al., 2001).

Rhizobacteria-mediated enhanced tolerance to environmental stresses has been suggested as one of eco-friendly strategies for crop production under harsh environmental conditions (Yang et al., 2009). Pepper plants have acquired increased tolerance during water deficit stress by Bacillus licheniformis K11 treatment in soils (Lim and Kim, 2013). Co-treatment with three different bacterial species Bacillus cereus AR156, B. subtilis SM21 and Serratia sp. XY21 induced drought tolerance in cucumber plants (Wang et al., 2012). B. amyloliquefaciens Bk7 and Brevibacillus laterosporus $\mathrm{B} 4$ synergistically increased survival of rice plants under dehydration stress (Kakar et al., 2016). Heat stress could be alleviated by in Pseudomonas sp. AKM-P6treated sorghum plants and Pseudomonas putida AKMP7treated wheat plants (Ali et al., 2009, 2011). But the beneficial microbe-mediated enhanced tolerance to high temperature stress was hardly found in plants. Plants are occasionally suffered from drought and high temperature stresses simultaneously during their growth. Physiological changes have occurred in citrus, tomato, barley and maize plants under combined drought and high temperature stress conditions (Templer et al., 2017; Zandalinas et al., 2016; Zhao et al., 2016; Zhou et al., 2017). However, it has not been investigated yet whether introducing microbes in the rhizosphere reduces loss or damage from the combined drought and high temperature stresses.

Plant diseases have been efficiently controlled by introducing rhizobacteria into the growing soils. In particular, Bacillus species have been demonstrated for disease suppressions in many crops and various Bacillus-producing lipopeptides played pivotal roles in the crop protections (Ongena and Jacques, 2008; Shafi et al., 2017). However, only a few Bacillus-mediated disease controls was demonstrated in Chinese cabbage plants. Chinese cabbage bottom rot caused by Rhizoctonia solani was reduced by $B$. amuloliquefaciens subsp. plantarum GR53 treatment (Kang et al., 2015). Suppressed bacterial soft rot of Chinese cabbage was mediated by $B$. toyonensis CAB12243-2 and $B$. vallismortis BS07M (Kim et al., 2018; Sang et al., 2015). Fungi Alternaria brassicicola and Colletotrichum higginsianum caused black spot and anthracnose diseases on Chinese cabbage plants, respectively. B. amyloliquefaciens UCM5113 and its lipopeptide extracts have in vitro antifungal activity against $A$. brassicicola (Asari et al., 2017). $B$. subtilis BCA31 and its culture filtrate markedly inhibited in vitro mycelial growth of $C$. higginsianum (Rakotoniriana et al., 2013). However, no biocontrol has been established on Chinese cabbage plants against the two fungal infections.

Although a variety of Bacillus spp. have exhibited their capability in soils to confer stress tolerance and disease resistance in plants, a few studies reported roles of Bacillus aryabhattai and Bacillus siamensis in enhanced plant stress tolerance. B. aryabhattai SRB02 improved significantly tolerance of soybean to heat stress by elevating gibberellic acid (GA) 4, GA7, GA12 and jasmonic acid levels (Park et al., 2017). B. aryabhattai LMA3 promoted growth of Zea mays under water deficit stress (Kavamura et al., 2013). Although draft genome sequence of Bacillus siamensis KCTC $13613^{\mathrm{T}}$ as a plant growth-promoting bacterium was reported, any experimental evidence was not supported (Jeong et al., 2012).

In this study, roles of B. aryabhattai $\mathrm{H} 26-2$ and B. siamensis $\mathrm{H} 30-3$ in protecting Chinese cabbage plant against high temperature and/or drought stresses were investigated. In vitro antifungal activities and crop protection efficacies of the B. siamensis H30-3 species against Alternaria brassicicola and Colletotrichum higginsianum were also investigated.

\section{Materials and Methods}

Plant growth. Seeds of two Chinese cabbage (Brassica rapa subsp. pekinensis) cultivars Ryeokgwang and Buram3 -ho were sown in plastic pots $(6 \mathrm{~cm}$ in diameter, $5.5 \mathrm{~cm}$ in height) containing commercial soil mixtures (Toshil, Shinan Growth Co. Ltd., Republic of Korea). The seedlings were raised in a plastic greenhouse or in environmentally controlled walk-in growth chambers at $24 \pm 2^{\circ} \mathrm{C}$ under a 12 $\mathrm{h}$ photoperiod.

Bacterial cultures and inoculation. Bacillus aryabhattai H26-2 and Bacillus siamensis H30-3 were isolated from rhizosphere of tomato plants grown in Sacheon, Gyeongnam Province. After being identified using physiological and molecular procedures, they were deposited in Korean 
Agricultural Culture Collection as KACC 92165P and KACC 92187P, respectively. They were subcultured on nutrient agar (NA) media at $30^{\circ} \mathrm{C}$. The two Bacillus species were inoculated in nutrient broth and cultured overnight by shaking at $30^{\circ} \mathrm{C}$. The concentrations of bacterial suspensions in sterile water were adjusted to $4 \times 10^{7} \mathrm{cfu} /$ $\mathrm{ml}$ using a spectrophotometer. Two-week-old Chinese cabbage seedlings in the pots were placed in the round plates ( $90 \mathrm{~mm}$ in diameter, $40 \mathrm{~mm}$ in height) containing $30 \mathrm{ml}$ of the bacterial suspensions, and then raised for additional one week for environmental stresses as indicated in the figure legends.

For crop protection against fungal infections, a bacterial suspension $\left(10^{9} \mathrm{cfu} / \mathrm{ml}\right)$ of B. siamensis $\mathrm{H} 30-3$ was foliarsprayed onto three-week-old Chinese cabbage plants $(5 \mathrm{ml}$ of the bacterial suspension per pot) at 1 day prior to fungal challenge inoculations.

High temperature and drought stresses on bacterial growth. B. aryabhattai strain $\mathrm{H} 26-2$ and $B$. siamensis strain H30-3 were cultured in $4 \mathrm{ml}$ of nutrient broth media supplemented with different doses of PEG $6000(0,4,12$ and $20 \%$ ) at 30,40 and $50^{\circ} \mathrm{C}$. In vitro growth of two phytopathogenic bacteria causing soft rot (Pectobacterium carotovorum subsp. carotovorum strain PCC21) and black rot (Xanthomonas campestris pv. campestris strain 8004) in Chinese cabbage plants were also evaluated to investigate different bacterial sensitivity under the same high temperature and/or drought stress conditions (Lee and Hong, 2012; Park et al., 2012). Bacterial inoculum density of the four bacterial suspensions was adjusted to $10^{5} \mathrm{cfu} / \mathrm{ml}$, and then optical densities at $600 \mathrm{~nm}$ were measured at $48 \mathrm{~h}$ after the liquid cultures.

High temperature and drought stresses of Chinese cabbage seedlings. Chinese cabbage seedlings were subjected to high temperature and/or drought stresses in a plastic greenhouse and environmentally controlled growth chambers.

To investigate growth of two Chinese cabbage cultivars under different ambient temperatures, seeds of two cultivars were sown in the pots at four different planting dates (4 Jul, 4 Aug, 5 Sep and 5 Oct) and grown for five weeks in the greenhouse. Thereafter, fresh weight $(\mathrm{FW})$ of the seedlings was measured. Maximum and minimum temperatures in the greenhouse were measured daily, and averages in the maximum, mean and minimum temperatures for five weeks were calculated. To prevent insect infestation, the plants were grown under a mosquito net in the greenhouse.

To compare tolerance of the two Chinese cabbage cul- tivars to drought stress, three-week-old Chinese cabbage seedlings were undergone by two different water-stress regimes: one-week and two-weeks. After five-weeks after planting, FW of the seedlings was measured. Mock was conducted by water irrigation.

For beneficial microbe-mediated enhanced drought stress tolerance of Chinese cabbage seedlings, three-week-old Chinese cabbage seedlings pretreated with the $B$. aryabhattai $\mathrm{H} 26-2$ or $B$. siamensis $\mathrm{H} 30-3$ were grown with continuous supplement of different PEG solutions (0,2 and 4\%) under usual growing temperature conditions. FW of the seedlings was measured at 12 days after PEG treatment.

For beneficial microbe-mediated high temperature tolerance of Chinese cabbage seedlings, the seedlings were transferred to growth chambers under the controlled environments: day/night temperatures maintained at $35 / 25^{\circ} \mathrm{C}$, $12 \mathrm{~h} \mathrm{light} / 12 \mathrm{~h}$ dark photoperiod, at $40 \%$ relative humidity in a growth cabinet. At five days after high temperature treatment, FW of the seedlings was measured.

For beneficial microbe-mediated tolerance to combined stresses of high temperature and drought, three-week-old Chinese cabbage seedlings pretreated with the $B$. aryabhattai $\mathrm{H} 26-2$ and $B$. siamensis $\mathrm{H} 30-3$ were cultivated with different PEG solutions (0, 2 and 4\%) under high temperature conditions described above. FW of the seedlings was measured at five days after PEG-high temperature treatment.

Phytopathogenic fungal cultures. Alternaria brassicicola MUCL 20297 and Colletotrichum higginsianum C97-28 (KACC 40807) were cultured on $1 / 2$-strength potato dextrose agar (PDA) medium at $25^{\circ} \mathrm{C}$ as previously described (Lee and Hong, 2014). Conidial suspension preparation and Chinese cabbage inoculation of the two fungal species were followed by the methods in our previous study (Lee and Hong, 2014).

In vitro dual cultures of Bacillus species with phytopathogenic fungi. Antifungal activity of $B$. aryabhattai H26-2 and B. siamensis $\mathrm{H} 30-3$ was evaluated against two Chinese cabbage fungal pathogens, $A$. brassicicola MUCL 20297 and C. higginsianum C97-28 (KACC 40807) on 1/2-strengh PDA plates. Two Bacillus strains H26-2 and $\mathrm{H} 30-3$ were grown in nutrient broth at $30^{\circ} \mathrm{C}$ overnight. The bacterial suspensions of strains H26-2 and H30-3 were prepared in sterile water and adjusted to $10^{8} \mathrm{cfu} / \mathrm{ml}$. The bacterial suspension was inoculated three times on one side on PDA and mycelial plug from A. brassicicola and C. higginsianum colonies was placed on the opposite side. The plates were incubated and radii of fungal colonies were measured after $15 \mathrm{~d}$ and $12 \mathrm{~d}$ for A. brassicicola and $C$. 
higginsianum, respectively.

Chinese cabbage inoculation and disease evaluations. Three-week-old Chinese cabbage seedlings were inoculated by foliar spraying conidial suspension $\left(2 \times 10^{5}\right.$ conidia/ $\mathrm{ml}$ ), and then placed in humid chamber for $24 \mathrm{~h}$ under dark condition. After the moist and dark periods, the plants were placed in growth room for symptom development. Disease was evaluated based on disease severity of 0-5 scales as follows: 0 , no symptom developed; 1 , several necrotic spots appeared; 2, primary true leaves blighted and necrotic spots appeared on other leaves; 3 , primary and secondary true leaves blighted and necrotic spots appeared on other leaves; 4, primary and secondary true leaves blighted and $50 \%$ of other leaves collapsed; 5 , whole plants completely dead.

Identification of cyclic lipopeptide biosynthetic genes in Bacillus spp.. B. aryabhattai $\mathrm{H} 26-2$ and B. siamensis H30-3 were characterised by the presence of six antimicrobial lipopeptide biosynthetic genes $b a c D, b m y A$, fenD, ituA, srfA and zwiA involved in producing bacilysin, bacillomycin $\mathrm{D}$, fengycin, iturin $\mathrm{A}$, surfactin and zwittrmicin A, respectively. Single colony from $B$. aryabhattai $\mathrm{H} 26-2$ and $B$. siamensis $\mathrm{H} 30-3$ cultures on NA media was isolated and re-suspended in sterile distilled water. One $\mu \mathrm{l}$ of the bacterial suspension was subjected to a template for PCR. Primer pairs demonstrated in Kim et al. (2016) for the six antimicrobial peptide biosynthetic genes were used. PCR amplifications were carried out in 50- $\mu 1$ reaction mixture. PCR products were subjected to gel electrophoresis containing 1.4\% agarose and RedSafe ${ }^{\mathrm{TM}}$ Nucleic Acid Staining Solution (iNtRON Biotechnology, Republic of Korea), visualised by UV-illumination and photographed (Kim et al., 2015b).

Production of hydrolytic enzymes and siderophore from Bacillus spp. and phosphate solubilisation ability. Production cellulase, protease and chitinase by $B$. aryabhattai $\mathrm{H} 26-2$ and B. siamensis $\mathrm{H} 30-3$ were analysed on carboxymethyl cellulose agar media, Luria-Bertani agar media supplemented with 3\% skim milk and colloidal chitin agar media, respectively (Han et al., 2015, 2017). Abilities of B. aryabhattai H26-2 and B. siamensis $\mathrm{H} 30-3$ siderophore production and phosphate solubilisation were performed on Chrome azurol S agar and Pikovskaya's agar media, respectively (Han et al., 2015, 2017).

RNA isolation and defence-related gene expression analysis in Chinese cabbage leaves. Total RNA isolation and semi-quantitative RT-PCR analysis were performed with the third true leaves from three-week-old Chinese cabbage seedlings treated with or without $B$. siamensis H30-3 according to the methods of our previous studies (Kim et al., 2015b; Lee and Hong, 2014). Total RNA was isolated from the leaf tissues using RiboEx solution (GeneAll Biotechnology, Co., Ltd., Seoul, Republic of Korea), and two micrograms of the total RNA was converted to cDNA using Superscript III reverse transcriptase and oligo $(\mathrm{dT})_{20}$ primer according to the manufacturer's instructions (Thermo Fisher Scientific, MA, USA). PCR amplification was performed by $95^{\circ} \mathrm{C}$ for $30 \mathrm{~s}, 52^{\circ} \mathrm{C}$ for $30 \mathrm{~s}$ and $72^{\circ} \mathrm{C}$ for $30 \mathrm{~s}$, with a final extension for $72^{\circ} \mathrm{C}$ for $10 \mathrm{~min}$. RT-PCR primers which had previously demonstrated for defence-related genes of Chinese cabbage plants were used (Lee and Hong, 2012). PCR cycles of each defence-related gene were described in right parenthesis of Fig. 5C. PCR products were agarose gel electrophoresis and visualised as described above.

Statistical analyses. Error bars represent the standard errors of the means of the four independent experimental replications. Each experiment was conducted with four replications. Data were subjected to analysis of variance using SAS version 9.1 (SAS Institute, Inc., Cary, NC, USA). Means were separated by least significant difference (LSD) test at $P<0.05$. Graphs were prepared using SigmaPlot 10.0 (Systat Software, Inc., San Jose, CA, USA).

\section{Results}

Different plant growth of two Chinese cabbage cultivars to high temperature and drought stresses. Tolerance of two Chinese cabbage cvs. 'Ryeokgwang' and 'Buram-3-ho' to different temperature and drought stress regimes were compared (Fig. 1).

No significant difference was found in growth of fiveweek-old two Chinese cabbage cultivars under growing conditions (data not shown). To investigate growth of the two cultivars under high temperature condition, the two cultivars planted at the four different sowing dates (4 Jul, 4 Aug, 5 Sep and 5 Oct) were compared in a plastic house (Fig. 1A). Sowing at 5 Sep resulted in most efficient growth in both cultivars, and followed by sowing at 4 Aug. Both cultivars planted at 4 Jul and 5 Oct showed delayed the plant growth with similar levels. 'Ryeokgwang' planted at 4 Aug and 5 Sep showed better plant growth than 'Buram-3-ho' planted at the same dates. Drought tolerance of two Chinese cabbage cultivars was compared by stopping water irrigation for 7 or 14 days (Fig. 1B). At two 
A
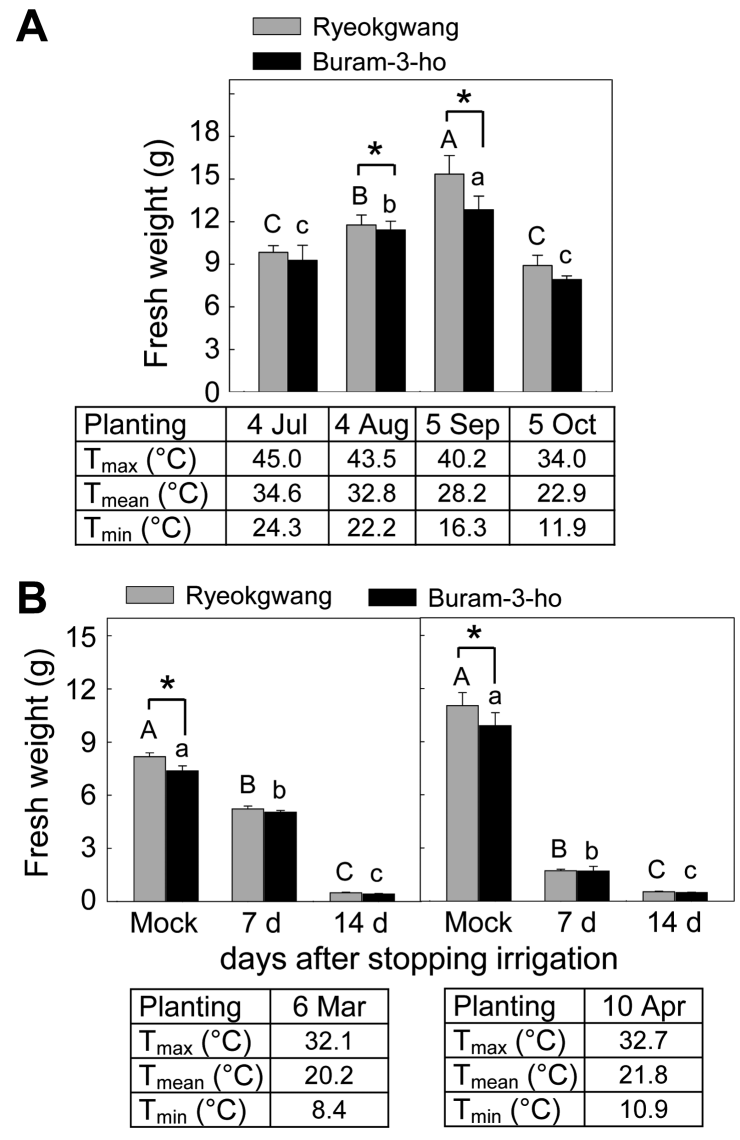

Fig. 1. Different sensitivity of two Chinese cabbage seedlings (cvs. Ryeokgwang and Buram-3-ho) to high temperature and/or drought stress under greenhouse conditions. (A) Plant growth of two cultivars grown for five weeks after planting at four different planting dates (4 Jul, 4 Aug, 5 Sep and 5 Oct) under a plastic greenhouse condition. Changes in average maximum $\left(\mathrm{T}_{\max }\right)$, average mean $\left(\mathrm{T}_{\text {mean }}\right)$ and average minimal $\left(\mathrm{T}_{\text {min }}\right)$ temperatures $\left({ }^{\circ} \mathrm{C}\right)$ for five weeks under the greenhouse conditions were demonstrated. (B) Plant growth of two Chinese cabbage cultivars by stopping irrigations. Three-week-old seedlings were undergone different irrigation regimes for additional two-weeks. Error bars represent the standard errors of the means of the four independent experimental replications. Means followed by the same letter are not significantly different at $5 \%$ level by least significant difference test.

different sowing dates (6 Mar and 10 Apr), 'Ryeokgwang' grew better with higher FW than 'Buram-3-ho' with normal water irrigation (mock). However, no significant difference in plant growth of two cultivars was found at 7 or 14 days after stopping watering, although stopping watering for 14 days showed much distinctly decreased FW of two cultivars than 7 days without watering.

Bacterial growth of two Bacillus species to drought and high temperature stresses. Tolerance of $B$. aryabhattai

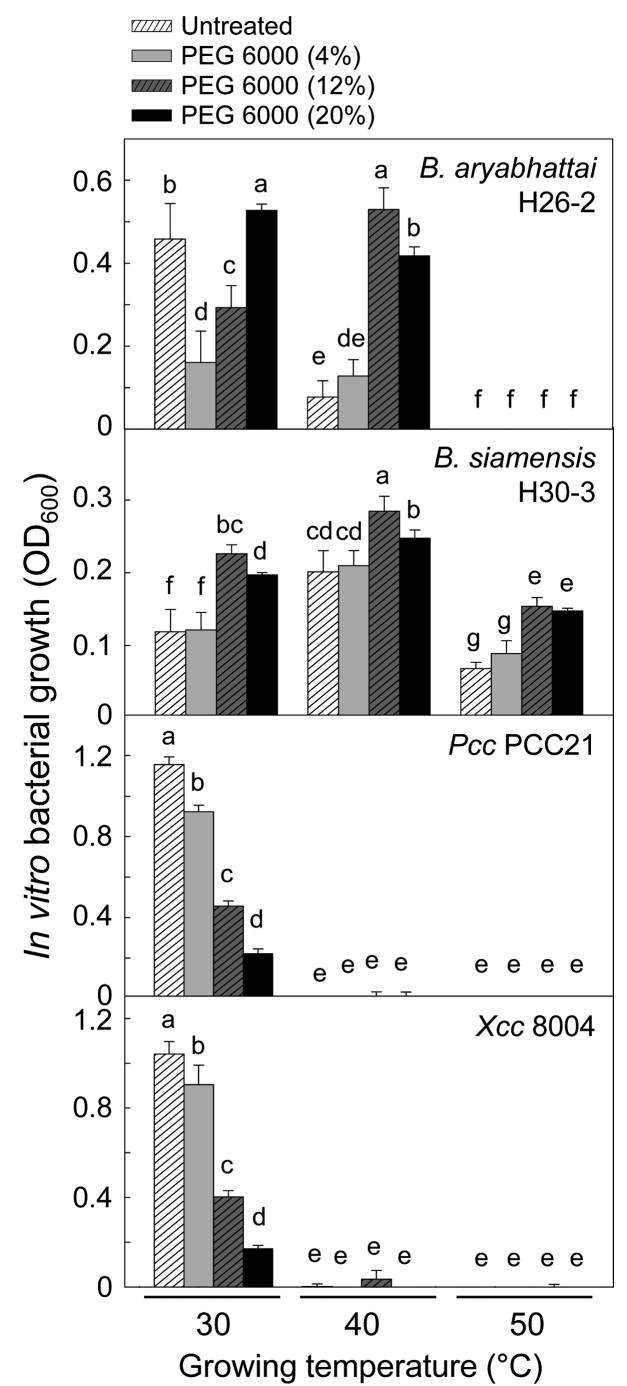

Fig. 2. Bacterial tolerance to dehydration at different growing temperatures during in vitro liquid cultures. Two Bacillus species (B. aryabhattai $\mathrm{H} 26-2$ and B. siamensis $\mathrm{H} 30-3)$ and two phytopathogenic bacteria Pectobacterium carotovorum subsp. carotovorum (Pcc) strain PCC21 and Xanthomonas campestris pv. campestris $(X c c)$ strain 8004 were cultured with increasing concentration $(0,4,12$ and 20\%) of polyethylene glycol (PEG) 6000 at different temperatures $\left(30,40\right.$ and $\left.50^{\circ} \mathrm{C}\right)$ for $48 \mathrm{~h}$. Bacterial numbers were initially inoculated with $10^{5} \mathrm{cfu} / \mathrm{ml}$ and indirectly measured using a spectrophotometer with optical density at 600 $\mathrm{nm}$. Error bars represent the standard errors of the means of the four independent experimental replications. Means followed by the same letter are not significantly different at $5 \%$ level by least significant difference test.

H26-2 and B. siamensis H30-3 against drought stress under different growing temperatures was evaluated (Fig. 2).

Growth of $B$. aryabhattai $\mathrm{H} 26-2$ was drastically suppressed by $4 \%$ PEG 6000 treatment at $30^{\circ} \mathrm{C}$ and increasing PEG 6000 concentration to $12 \%$ mitigated the arresting 
bacterial growth. Treatment with 20\% PEG 6000 rather increased the bacterial growth compared to the untreated control. The higher growth temperature $40^{\circ} \mathrm{C}$ without PEG 6000 treatment suppressed the growth of $B$. aryabhattai H26-2 compared to its growth at $30^{\circ} \mathrm{C}$. Supplement with $12 \%$ and $20 \%$ PEG 6000 enhanced the bacterial growth compared to the untreated control at $40^{\circ} \mathrm{C}$. No bacterial growth of $B$. aryabhattai $\mathrm{H} 26-2$ occurred at $50^{\circ} \mathrm{C}$ with or without PEG 6000 treatment.

Relatively higher concentrations of PEG 6000 treatment (12 and 20\%) accelerated B. siamensis $\mathrm{H} 30-3$ growth at

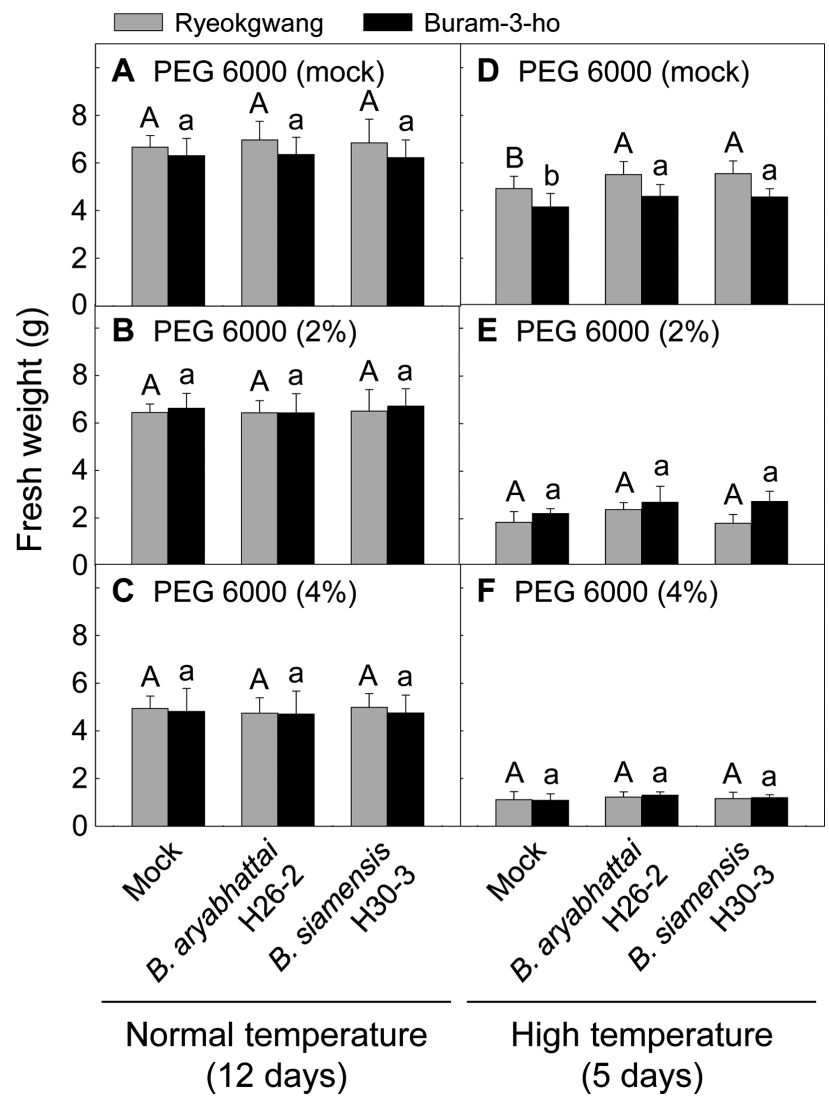

Fig. 3. Effect of pretreatment with rhizobacteria on growth of Chinese cabbage seedling (cvs. Ryeokgwang and Buram-3-ho) under drought stress at two different temperatures. Two-weekold seedlings were treated with Bacillus aryabhattai $\mathrm{H} 26-2$ and $B$. siamensis H30-3 for one week and then undergone different concentrations $(0,2$ and $4 \%$ ) of polyethylene glycol (PEG) 6000-mediated drought stresses under two growth temperature regimes. The seedlings were sub-irrigated with water as mocks. Fresh weight ( $\mathrm{g}$ ) of the seedlings was measured after 12 days and 5 days for normal and high temperature conditions, respectively. Error bars represent the standard errors of the means of the four independent experimental replications. Means followed by the same letter are not significantly different at $5 \%$ level by least significant difference test. each temperature $\left(30,40\right.$ and $\left.50^{\circ} \mathrm{C}\right)$. The highest growing temperature at $50^{\circ} \mathrm{C}$ generally delayed bacterial growth compared to the other growing temperatures.

$P c c$ PCC21 and $X c c 8004$ were grown well at $30^{\circ} \mathrm{C}$ without PEG 6000 treatment but increasing PEG 6000 resulted in suppressed bacterial growth in PEG dose-dependent manners. At 40 and $50^{\circ} \mathrm{C}$, growth of $P c c$ PCC 21 and Xcc 8004 was not detected.

High temperature and/or drought stress tolerance of two Chinese cabbage cultivars mediated by two Bacillus species. Tolerance of Chinese cabbage seedlings to high temperature and PEG 6000-mediated drought stresses was investigated by pretreatment with $B$. aryabhattai $\mathrm{H} 26-$ 2 and B. siamensis H30-3 (Fig. 3). Under normal growth temperature condition, any bacterial application did not influence plant growth with or without PEG 6000-mediated drought stress (Figs. 3A-C). Under high temperature condition without PEG 6000 treatment, i.e. under high temperature stress alone, B. aryabhattai $\mathrm{H} 26-2$ and B. siamensis $\mathrm{H} 30-3$ ameliorated the plant growth retardation in the two Chinese cabbage cultivars (Fig. 3D). However, the two Bacillus species did not confer any tolerance against combined stresses of high temperature and drought (Figs. 3E, F).

In vitro antifungal activity and in planta crop protection by $B$. siamensis strain H30-3. Potent disease control activities of $B$. aryabhattai $\mathrm{H} 26-2$ and $B$. siamensis $\mathrm{H} 30-$ 3 were analysed in in vitro dual culture assays as well as in Chinese cabbage seedlings inoculated by two fungal pathogens $A$. brassicicola and C. higginsianum (Fig. 4).

Only B. siamensis $\mathrm{H} 30-3$ showed in vitro antifungal activities against two fungal species infecting Chinese cabbage plants (Figs. 4A, B). Mycelial growth of $A$. brassicicola and $C$. higginsianum was significantly limited by B. siamensis H30-3. That was shown as reduced sizes of the fungal colonies on PDA media at $15 \mathrm{~d}$ and $12 \mathrm{~d}$ after co-cultivation. Pretreatment of Chinese cabbage seedlings with bacterial suspension of $B$. siamensis strain $\mathrm{H} 30-3$ resulted in reduced disease severity against $A$. brassicicola and $C$. higginsianum (Fig. 4C). At 4 days after the fungal challenge-inoculation, disease severity of black spot and anthracnose diseases was decreased by the $B$. siamensis H30-3 in ' Ryeokgwang', but not in 'Buram-3-ho'.

Biochemical and molecular characteristics of $B$. siamensis $\mathbf{H 3 0 - 3}$ for crop protection. Biological roles of $B$. siamensis $\mathrm{H} 30-3$ were investigated to see whether or not the bacterial strain produces antifungal metabolites and/or 


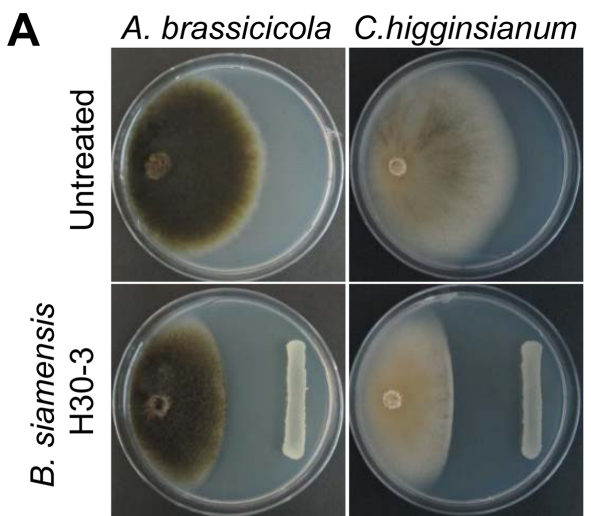

B
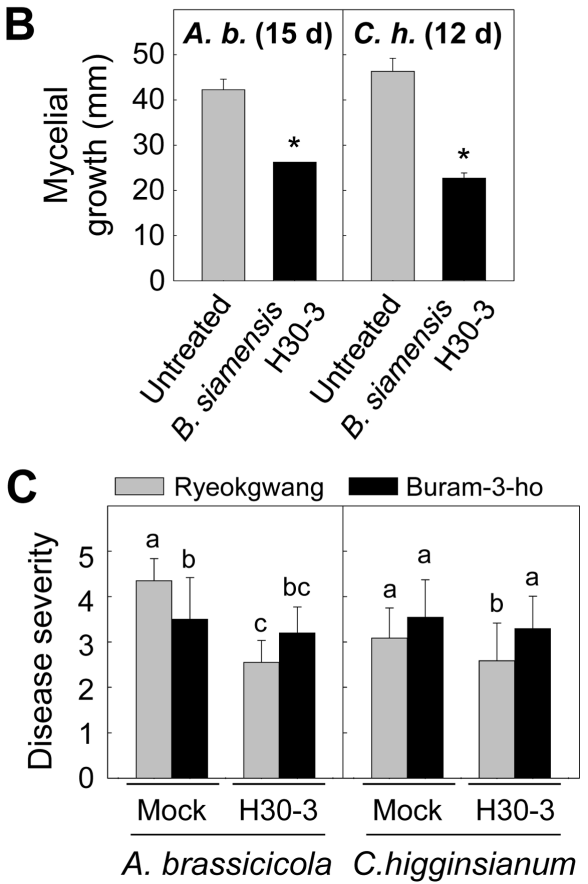

Fig. 4. Protective effects of Bacillus siamensis H30-3 against fungal pathogens on Chinese cabbage plants. (A) Dual culture assay for in vitro inhibition of mycelial growth of Alternaria brassicicola and Colletotrichum higginsianum by B. siamensis $\mathrm{H} 30-3$. The fungal pathogens were co-cultured with the bacterial strain $\mathrm{H} 30-3$ for 15 and 12 days at $25^{\circ} \mathrm{C}$ for $A$. brassicicola and $C$. higginsianum, respectively. (B) Inhibitory mycelial growth measured by half of the fungal colony diameter after co-culture. Error bars represent the standard errors of the means of the six independent experimental replications. Asterisks indicate significant differences as determined by Student's $t$-test $(P<0.05)$. (C) Reduced black spot and anthracnose disease severities on Chinese cabbage plants by the antagonistic $B$. siamensis H30-3. Bacterial suspension $\left(10^{9} \mathrm{cfu} / \mathrm{ml}\right)$ of $B$. siamensis $\mathrm{H} 30-3$ was foliar sprayed at 1 day prior to challenge inoculations of the fungal pathogens. Disease severities were evaluated at 4 days after fungal inoculation based on 0-5 scales. Error bars represent the standard errors of the means of the four independent experimental replications. Means followed by the same letter are not significantly different at $5 \%$ level by least significant difference test. activates plant defence response (Fig. 5).

Nucleotide sequences for putative genes homologous to several genes involved in biosynthesis of cyclic lipopeptides were found in the $B$. siamensis H30-3 genome, whereas none of cyclic lipopeptide genes was detected in the $B$. aryabhattai H26-2 genome (Fig. 5A). The bacterial genes homologous to $b a c D, b m y A$, itu $A$ and $\operatorname{srf} A$ were detected in B. siamensis H30-3, whilst PCR products for genes homologous to fenD and $z w i A$ were not amplified.

Several hydrolytic enzyme activities were uncovered on the media where B. siamensis H30-3 was grown (Fig. 5B). Strong protease and cellulase activities and relatively low chitinase activity were shown by in vitro culture of $B$. siamensis $\mathrm{H} 30-3$. Siderophore production from B. siamensis H30-3 was also revealed, but phosphate-solubilisation activity was not found.

Several defence-related genes in the two cultivars of Chinese cabbage leaves were differently regulated with or without B. siamensis H30-3 treatment (Fig. 5C). BrChil and $B r G S T 1$ expressions were up-regulated in the Chinese cabbage leaves treated with $B$. siamensis $\mathrm{H} 30-3$ at 1 day after foliar spraying the bacterial suspension. The induced level of BrChil expression was similar in the two cultivars, but inducible BrGST1 expression was higher in 'Ryeokgwang' than in 'Buram-3-ho'. BrLOX2 gene expression was slightly higher in 'Ryeokgwang' than in 'Buram-3-ho' without H30-3 treatment. Pretreatment with the H30-3 did not alter the BrLOX2 gene expression in 'Ryeokgwang', but increased the expression in 'Buram-3-ho'. Expression of BrBGL2 and BrAPX1 genes was not altered by the bacterial treatment.

\section{Discussion}

Global concerns are increasing due to reduced crop yields under recent detrimental climate changes. In particular, elevated temperature and limited irrigation in crop fields decreased appropriate cultivation areas for crops (Fahad et al., 2017). Changing environments such as increased $\mathrm{CO}_{2}$ level and temperature affect crop susceptibility to pathogen attacks and crop production (Elad and Pertot, 2014; Gregory et al., 2009). Chinese cabbage, a major vegetable crop in several countries, is one of the crops encountering adverse agricultural environmental changes; high temperature and drought climate have limited the vegetative growth and seed yields in recent decades (Angadi et al., 2000; Lee et al., 2016; Oh et al., 2014; Sammis et al., 1988; Yan, 2015).

A variety of bacterial species interacts with plants in the rhizosphere and often mediates beneficial effects by promoting plant growth and activating plant defence responses 


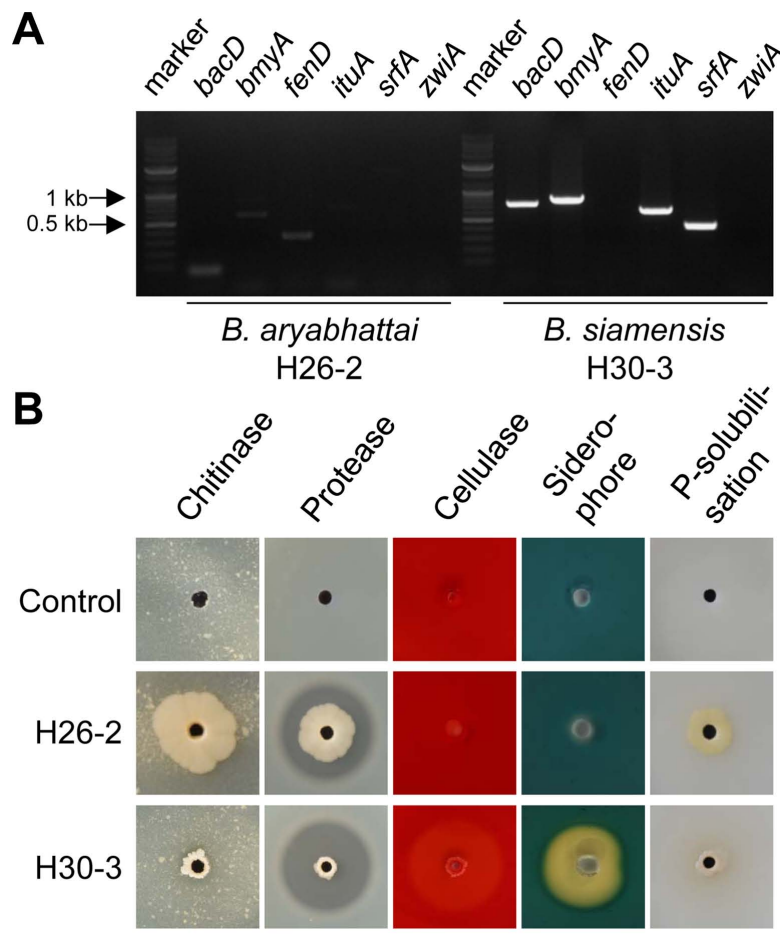

C

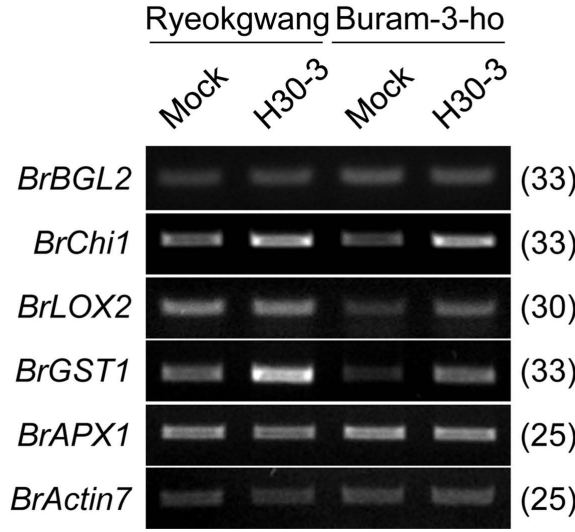

Fig. 5. Antifungal metabolites production and induced defence response of Chinese cabbage plants by Bacillus siamensis $\mathrm{H} 30$ 3. (A) PCR-based detection of bacterial genes encoding antimicrobial lipopeptides from $B$. aryabhattai $\mathrm{H} 26-2$ and B. siamensis H30-3 genomes. M, DNA size marker. $b a c D$, bacilysin; bmyA, bacillomycin; fenD, fengycin; ituA, iturin A; srfA, surfactin; zwiA, zwittermicin A. (B) Characteristics of hydrolytic enzyme secretion, siderophore production and phosphate $(\mathrm{P})$-solubilisation originated from $B$. siamensis $\mathrm{H} 30-3$. In vitro productions of chitinase, protease and cellulase by $B$. siamensis $\mathrm{H} 30-3$ were examined on different agar media described in Materials and methods. (C) Expression of defence-related genes in Chinese cabbage leaves treated with $B$. siamensis H30-3. Expression of basic glucanase 2 gene $B r B G L 2$, chitinase 1 gene $B r C h i 1$, glutathione$S$-transferase 1 gene $B r G S T 1$ and ascorbate peroxidase 1 gene $B r A P X 1$ was analyzed by semi-quantitative RT-PCR technique. BrActin 7 was used as an internal control. The number of PCR cycles of each result is indicated within the right parenthesis. against abiotic stresses and/or pathogen attacks, which lead to improved production in many economically important crops (Maksimov et al., 2011; Ngumbi and Kloepper, 2016; Yang et al., 2009; Yoo and Sang, 2017). Different Bacillus species have shown increased tolerance of various crops to environmental stresses including drought, high salinity and high temperature (Abd_Allah et al., 2017; Lim and Kim, 2013; Nautiyal et al., 2013; Park et al., 2017; Timmusk et al., 2014). Rhizobacteria-induced high temperature stress tolerance was only described in soybean plants, which was mediated by B. aryabhattai strain SRB02 (Park et al., 2017). Changes in phytohormones and abscisic acidrelated gene expressions were demonstrated during the high temperature stress tolerance of soybean plants. In this study, two rhizobacteria $B$. aryabhattai $\mathrm{H} 26-2$ and $B$. siamensis H30-3 applied to two Chinese cabbage cultivars enhanced tolerance in response to high temperature stress. Heat stress led to various physiological and molecular changes in Brassicaceae plants. Differential glucosinolate volatiles were released in Brassica nigra plants in response to three different heat stress regimes (Kask et al., 2016). Highly activated antioxidant enzymes peroxidase and catalase were closely associated with heat tolerance of $B$. juncea plants (Wilson et al., 2014). Several genes encoding putative nucleotide-binding proteins showed higher expressions in heat-resistant $B$. oleracea line compared to those in heat-susceptible one (Kim et al., 2015c). Recently, differentially expressed genes were demonstrated in heatsusceptible and -tolerant Chinese cabbage genotypes in response to heat shock (Dong et al., 2015). However, no mechanism of rhizobacteria-mediated heat stress tolerance has been investigated in Brassica plants yet. Study of the biochemical and molecular changes in the Chinese cabbage plants during the two Bacillus strains-mediated stress tolerance to chronic high temperature is helpful to understand the mode-of-action in regulating the stress response.

B. aryabhattai $\mathrm{H} 26-2$ and $B$. siamensis $\mathrm{H} 30-3$ were themselves relatively more tolerant to high temperature and dehydration conditions compared to two phytopathogenic bacteria Pcc and Xcc (Fig. 2). 'Ryeokgwang' had relatively higher tolerance to high temperature compared to 'Buram3-do' under greenhouse conditions, but no difference was found in drought tolerance (Fig. 1). B. aryabhattai H26-2 and B. siamensis H30-3 increased stress tolerance of two cultivars to high temperature, but not drought. No beneficial effect of the two rhizobacteria was found against combined stress of high temperature and drought stress (data not shown).

B. siamensis $\mathrm{H} 30-3$ pretreatment protected Chinese cabbage cv. 'Ryeokgwang' against black spot and anthracnose 
diseases (Fig. 4C). Crop protection by B. siamensis has not been described so far, although biological controls by various Bacillus species such as B. subtilis, B. amyloliquefaciens and $B$. vallismortis have been prevalently demonstrated in many crops (Shafi et al., 2017). Reduced black rot and anthracnose of the Chinese cabbage plants may result from production of many antifungal metabolites produced by the B. siamensis H30-3 (Fig. 5). Presence of cyclic lipopeptides biosynthetic gene homologues suggests that cyclic lipopeptides such as bacilysin, bacillomycin, iturin and surfactin may be involved in antifungal activity of the H30-3 strain against $A$. brassicicola and $C$. higginsianum (Ongena and Jacques, 2008; Shafi et al., 2017). Although homologous nucleotide sequences to cyclic lipopeptides biosynthetic genes were detected in the $B$. siamensis H303 genome, molecular structures and antifungal activities of cyclic lipopeptides secreted from the H30-3 strain remains elucidated. Secreting hydrolytic enzymes such as chitinase and protease from $B$. siamensis $\mathrm{H} 30-3$ might be involved in the induced crop protection of Chinese cabbage plants through the direct antifungal activities against the fungal cell walls and proteins (Alamri, 2015; Neeraja et al., 2010; Reyes-Ramírez et al., 2004). Capability to produce extracellular cellulase and siderophore was found in the $B$. siamensis $\mathrm{H} 30-3$, which suggests that the strain $\mathrm{H} 30-3$ may also apply to Chinese cabbage plants to cope with invading pathogens containing cellulose in their structures (e.g. Hyaloperonospora parasitica) and pathogens requiring iron for their growths (e.g. Fusarium oxysporum f. sp. conglutinans) (Ahmad et al., 2017; Duijff et al., 1993; Sherriff and Lucas, 1990; Slusarenko and Schlaich, 2003; Sulochana et al., 2014). Applications of the H30-3 to the Chinese cabbage for disease management of downy mildew and $\mathrm{Fu}-$ sarium wilt remains investigated.

Enhanced plant defence reactions by the $B$. siamensis H30-3 could not be excluded, because pathogenesis-related genes such as BrChil and BrGSTl were expressed in Chinese cabbage leaves pretreated with the strain $\mathrm{H} 30-3$ before the fungal challenge inoculation (Fig. 5C). It is supported by the facts that BrChil and $B r G S T 1$ gene expressions were pathogen-inducible in two Chinese cabbage cultivars by $C$. higginsianum and $A$. brassicicola infections in our previous study (Lee and Hong, 2014). Induced BrChil expressions were found in the two Chinese cabbage cultivars with a similar level. B. siamensis $\mathrm{H} 30-3$ produced its own chitinase as well as mediated induced chitinase gene expression in Chinese cabbage plants. Highly inducible BrGST1 gene expression might be more closely associated with the H30-3-meidated crop protection in 'Ryeokgwang' through glutathione-dependent detoxification and/or de- fence signalling activation (Dixon et al., 2002). Enhanced defence-related gene expressions by Bacillus species in tobacco plants were consistent with our present results (Kim et al., 2015a; Park et al., 2001; Wang et al., 2016). One or more of the cyclic lipopeptides or peptides secreted from the B. siamensis $\mathrm{H} 30-3$ can be molecular determinants for eliciting disease resistance of Chinese cabbage plants (Ongena et al., 2007; Wang et al., 2016). Recently, it was demonstrated that volatiles emitted by Bacillus spp. played roles in plant growth promotion and crop protection (Asari et al., 2016; Fincheira and Quiroz, 2018; Tahir et al., 2017). B. siamensis H30-3-mediated volatiles for disease resistance of Chinese cabbage plants remains elucidated as well.

Taken together, rhizobacteria $B$. aryabhattai $\mathrm{H} 26-2$ and $B$. siamensis H30-3 enhanced tolerance of Chinese cabbage seedlings to high temperature stress. B. siamensis $\mathrm{H} 30-3$ also showed protective efficacies on Chinese cabbage seedlings against $A$. brassicicola and $C$. higginsianum infections. The current study will provide more insights on the rhizobacteria-mediated crop protection against abiotic and biotic stresses in Chinese cabbage plants.

\section{Acknowledgments}

This research was supported by a grant from Program (grant no. PJ0125172018), Rural Development Administration, Republic of Korea.

\section{References}

Abd_Allah, E. F., Alqarawi, A. A., Hashem, A., Radhakrishnan, R., Al-Huqail, A. A., Al-Otibi, F. O. N., Malik, J. A., Alharbi, R. I. and Egamberdieva, D. 2017. Endophytic bacterium $B a-$ cillus subtilis (BERA 71) improves salt tolerance in chickpea plants by regulating the plant defense mechanisms. J. Plant Interact. 13:37-44.

Ahmad, Z., Wu, J., Chen, L. and Dong, W. 2017. Isolated Bacillus subtilis strain 330-2 and its antagonistic genes identified by the removing PCR. Sci. Rep. 7:1777.

Alamri, S. A. 2015. Enhancing the efficiency of the bioagent Bacillus subtilis JF419701 against soil-borne phytopathogens by increasing the productivity of fungal cell wall degrading enzymes. Arch. Phytopathol. Plant Protect. 48:159-170.

Ali, S. Z., Sandhya, V., Grover, M., Kishore, N., Venkateswar Rao, L. and Venkateswarlu, B. 2009. Pseudomonas sp. strain AKM-P6 enhances tolerance of sorghum seedlings to elevated temperatures. Biol. Fertil. Soils 46:45-55.

Ali, S. Z., Sandhya, V., Grover, M., Venkateswar Rao, L. and Venkateswarlu, B. 2011. Effect of inoculation with a thermotolerant plant growth promoting Pseudomonas putida strain AKMP7 on growth of wheat (Triticum spp.) under heat stress. 
J. Plant Interact. 6:239-246.

Angadi, S. V., Cutforth, H. W., Miller, P. R., McConkey, B. G., Entz, M. H., Brandt, S. A. and Volkmar, K. M. 2000. Response of three Brassica species to high temperature stress during reproductive growth. Can. J. Plant Sci. 80:693-701.

Asari, S., Matzén, S., Petersen, M. A., Bejai, S. and Meijer, J. 2016. Multiple effects of Bacillus amyloliquefaciens volatile compounds: plant growth promotion and growth inhibition of phytopathogens. FEMS Microbiol. Ecol. 92:fiw070.

Asari, S., Ongena, M., Debois, D., De Pauw, E., Chen, K., Bejai, S. and Meijer, J. 2017. Insights into the molecular basis of biocontrol of Brassica pathogens by Bacillus amyloliquefaciens UCMB5113 lipopeptides. Ann. Bot. 120:551-562.

Dixon, D. P., Lapthorn, A. and Edwards, R. 2002. Plant glutathione transferases. Genome Biol. 3:3004.1-3004.10.

Dong, X., Yi, H., Lee, J., Nou, I. S., Han, C. T. and Hur, Y. 2015. Global gene-expression analysis to identify differentially expressed genes critical for the heat stress response in Brassica rapa. PLoS One 10:e130451.

Duijff, B. J., Meijer, J. W., Bakker, P. A. H. M. and Schippers, B. 1993. Siderophore-mediated competition for iron and induced resistance in the suppression of fusarium wilt of carnation by fluorescent Pseudomonas spp. Neth. J. Plant Pathol. 99:277289.

Elad, Y. and Pertot, I. 2014. Climate change impacts on plant pathogens and plant diseases. J. Crop Improv. 28:99-139.

Fahad, S., Bajwa, A. A., Nazir, U., Anjum. S. A., Farooq, A., Zohaib, A., Sadia, S., Nasim, W., Adkins, S., Saud, S., Ihsan, M. Z., Alharby, H., Wu, C., Wang, D. and Huang, J. 2017. Crop production under drought and heat stress: plant responses and management options. Front. Plant Sci. 8:1147.

Fincheira, P. and Quiroz, A. 2018. Microbial volatiles as plant growth inducers. Microbiol. Res. 208:63-75.

Gregory, P. J., Johnson, S. N., Newton, A. C. and Ingram, J. S. 2009. Integrating pests and pathogens into the climate change/food security debate. J. Exp. Bot. 60:2827-2838.

Han, J.-H., Shim, H., Shin, J.-H. and Kim, K. S. 2015. Antagonistic activities of Bacillus spp. strains isolated from tidal flat sediment towards anthracnose pathogens Colletotrichum acutatum and C. gloeosporioides in South Korea. Plant Pathol. J. 31:165-175.

Han, J.-H., Park, G.-C. and Kim, K. S. 2017. Antagonistic evaluation of Chromobacterium sp. JH7 for biological control of ginseng root rot caused by Cylindrocarpon destructans. Mycobiololgy 45:370-378.

Jeong, H., Jeong, D.-E., Kim, S. H., Song, G. C., Park, S.-Y., Ryu, C.-M., Park, S.-H. and Choi, S.-K. 2012. Draft genome sequence of the plant growth-promoting bacterium Bacillus siamensis KCTC $13613^{\mathrm{T}}$. J. Bacteriol. 194:4148-4149.

Kakar, K. U., Ren, X.-L., Nawaz, Z., Cui, Z.-Q., Li, B., Xie, G.L., Hassan, M. A., Ali, E. and Sun, G.-C. 2016. A consortium of rhizobacterial strains and biochemical growth elicitors improve cold and drought stress tolerance in rice (Oryza sativa L.). Plant Biol. 18:471-483.
Kang, S.-M., Radhakrishnan, R. and Lee, I. J. 2015. Bacillus amyloliquefaciens subsp. plantarum GR53, a potent biocontrol agent resists Rhizoctonia disease on Chinese cabbage through hormonal and antioxidants regulation. World J. Microbiol. Biotechnol. 31:1517-1527.

Kask, K., Kännaste, A., Talts, E., Copolovici, L. and Niinemets, Ü. 2016. How specialized volatiles respond to chronic and shortterm physiological and shock heat stress in Brassica nigra. Plant Cell Environ. 39:2027-2042.

Kavamura, V. N., Santos, S. N., da Silva, J. L., Parma, M. M., Ávila, L. A., Visconti, A., Zucchi, T. D., Taketani, R. G., Andreote, F. D. and de Melo, I. S. 2013. Screening of Brazilian cacti rhizobacteria for plant growth promotion under drought. Microbiol. Res. 168:183-191.

Kim, B.-R., Park, M.-S., Han, K.-S., Hahm, S.-S., Park, I.-H. and Song, J.-K. 2018. Biological control using Bacillus toyonensis strain CAB12243-2 against soft rot on Chinese cabbage. Korean J. Organic Agric. 26:129-140.

Kim, J.-S., Lee, J., Lee, C.-H., Woo, S. W., Kang, H., Seo, S.G. and Kim, S.-H. 2015a. Activation of pathogenesis-related genes by the rhizobacterium, Bacillus sp. JS, which induces systemic resistance in tobacco plants. Plant Pathol. J. 31:195201.

Kim, S. Y., Sang, M. K., Weon, H.-Y., Jeon, Y.-A., Ryoo, J. H. and Song, J. 2016. Characterization of multifunctional Bacillus sp. GH1-13. Korean J. Pestic. Sci. 20:189-196 (in Korean).

Kim, Y. J., Lee, Y. H., Lee, H.-J., Jung, H. and Hong, J. K. 2015 b. $\mathrm{H}_{2} \mathrm{O}_{2}$ production and gene expression of antioxidant enzymes in kimchi cabbage (Brassica rapa var. glabra Regel) seedlings regulated by plant development and nitrosative stresstriggered cell death. Plant Biotechnol. Rep. 9:67-78.

Kim, Y.-W., Jung, H.-J., Park, J.-I., Hur, Y. and Nou, I.-S. 2015c. Response of NBS encoding resistance genes linked to both heat and fungal stress in Brassica oleracea. Plant Physiol. Biochem. 86:130-136.

Lee, S. G., Lee, H. J., Kim, S. K., Choi, C. S., Park, S. T., Jang, Y. A. and Do, K. R. 2015. Effects of vernalization, temperature, and soil drying periods on the growth and yield of Chinese cabbage. Korean J. Hortic. Sci. Technol. 33:820-828.

Lee, S. G., Lee, H. J., Kim, S. K., Choi, C. S. and Park, S. T. 2016. Influence of waterlogging period on the growth, physiological responses, and yield of kimchi cabbage. J. Environ. Sci. Int. 25:535-542 (in Korean).

Lee, Y. H. and Hong, J. K. 2012. Host and non-host resistance of kimchi cabbage against different Xanthomonas campestris pathovars. Plant Pathol. J. 28:322-329.

Lee, Y. H. and Hong, J. K. 2014. Differential defence responses of susceptible and resistant kimchi cabbage cultivars to anthracnose, black spot and black rot diseases. Plant Pathol. 64:406-415.

Lim, J.-H. and Kim, S.-D. 2013. Induction of drought stress resistance by multi-functional PGPR Bacillus licheniformis K11 in pepper. Plant Pathol. J. 29:201-208. 
Maksimov, I. V., Abizgil'dina, R. R. and Pusenkova, L. I. 2011. Plant growth promoting rhizobacteria as alternative to chemical crop protectors from pathogens (Review). Appl. Biochem. Microbiol. 47:333-345.

Nautiyal, C. S., Srivastava, S., Chauhan, P. S., Seem, K., Mishra, A. and Sopory, S. K. 2013. Plant growth-promoting bacteria Bacillus amyloliquefaciens NBRISN13 modulates gene expression profiles of leaf and rhizosphere community in rice during salt stress. Plant Physiol. Biochem. 66:1-9.

Neeraja, C., Anil, K., Purushotham, P., Suma, K., Sarma, P. V. S. R. N., Moerschbacher, B. M. and Podile, A. R. 2010. Biotechnological approaches to develop bacterial chitinases as a bioshield against fungal diseases of plants. Crit. Rev. Biotechnol. 30:231-241.

Ngumbi, E. and Kloepper, J. 2016. Bacterial-mediated drought tolerance: Current and future prospects. Appl. Soil Ecol. 105:109-125.

Oh, S., Moon, K. H., Son, I.-C., Song, E. Y., Moon, Y. E. and Koh, S. C. 2014. Growth, photosynthesis and chlorophyll fluorescence of Chinese cabbage in response to high temperature. Korean J. Hort. Sci. Technol. 32:318-329. (in Korean)

Ongena, M. and Jacques, P. 2008. Bacillus lipopeptides: versatile weapons for plant disease biocontrol. Trend Microbiol. 16:115-125.

Ongena, M., Jourdan, E., Adam, A., Paquot, M., Brans, A., Joris, B., Arpigny, J.-L. and Thonart, P. 2007. Surfactin and fengycin lipopeptides of Bacillus subtilis as elicitors of induced systemic resistance in plants. Environ. Microbiol. 9:10841090.

Park, K., Ahn, I.-P. and Kim, C.-H. 2001. Systemic resistance and expression of the pathogenesis-related genes mediated by the plant growth-promoting rhizobacterium Bacillus amyloliquefaciens EXTN-1 against anthracnose disease in cucumber. Mycobiology 29:48-53.

Park, T. -H., Choi, B. -S., Choi, A. -Y., Choi, I. -Y., Heu, S. and Park, B. -S. 2012. Genome sequence of Pectobacterium carotovorum subsp. carotovorum strain PCC21, a pathogen causing soft rot in Chinese cabbage. J. Bacteriol. 194:6345-6346.

Park, Y.-G., Mun, B.-G., Kang, S.-M., Hussain, A., Shahzad, R., Seo, C.-W., Kim, A.-Y., Lee, S.-U., Oh, K. Y., Lee, D. Y., Lee, I.-J. and Yun, B. W. 2017. Bacillus aryabhattai SRB02 tolerates oxidative and nitrosative stress and promotes the growth of soybean by modulating the production of phytohormones. PLoS One 12:e173203.

Rakotoniriana, E. F., Rafamantanana, M., Randriamampionona, D., Rabemanantsoa, C., Urveg-Ratsimamanga, S., El Jaziri, M., Munaut, F., Corbisier, A.-M., Quetin-Leclercq, J. and Declerck, S. 2013. Study in vitro of the impact of endophytic bacteria isolated from Centella asiatica on the disease incidence caused by the hemibiotrophic fungus Colletotrichum higginsianum. Antonie Van Leeuwenhoek 103:121-133.

Reyes-Ramírez, A., Escudero-Abarca, B. I., Aguilar-Uscanga, G., Hayward-Jones, P. M. and Barboza-Corona, J. E. 2004. Antifungal activity of Bacillus thuringiensis chitinase and its potential for the biocontrol of phytopathogenic fungi in soybean seeds. J. Food Sci. 69:M131-M134.

Sammis, T. W., Kratky, B. A. and Wu, I. P. 1988. Effects of limited irrigation on lettuce and Chinese cabbage yields. Irrigation Sci. 9:187-198.

Sang, M. K., Dutta, S. and Park, K. 2015. Influence of commercial antibiotics on biocontrol of soft rot and plant growth promotion in Chinese cabbages by Bacillus vallismortis EXTN1 and BS07M. Res. Plant Dis. 21:255-260.

Shafi, J., Tian, H. and Ji, M. 2017. Bacillus species as versatile weapons for plant pathogens: a review. Biotechnol. Biotechnol. Equip. 31:446-459.

Sherriff, C. and Lucas, J. A. 1990. The host range of isolates of downy mildew, Peronospora parasitica, from Brassica crop species. Plant Pathol. 39:77-91.

Slusarenko, A. J. and Schlaich, N. L. 2003. Downy mildew of Arabidopsis thaliana caused by Hyaloperonospora parasitica (formerly Peronospora parasitica). Mol. Plant Pathol. 4:159170.

Sulochana, M. B., Jayachandra, S. Y., Kumar, S. K. A. and Dayanand, A. 2014 Antifungal attributes of siderophore produced by the Pseudomonas aeruginosa JAS-25. J. Basic Microbiol. 54:418-424.

Sun, C., Johnson, J. M., Cai, D., Sherameti, I., Oelmüller, R. and Lou, B. 2010. Piriformospora indica confers drought tolerance in Chinese cabbage leaves by stimulating antioxidant enzymes, the expression of drought-related genes and the plastid-localized CAS protein. J. Plant Physiol. 167:10091017.

Tahir, H. A. S., Gu, Q., Wu, H., Niu, Y., Huo, R. and Gao, X. 2017. Bacillus volatiles adversely affect physiology and ultrastructure of Ralstonia solanacearum and induce systemic resistance in tobacco against bacterial wilt. Sci. Rep. 7:40481.

Templer, S. E., Ammon, A., Pscheidt, D., Ciobotea, O., Schuy, C., McCollum, C., Sonnewald, U., Hanemann, A., Förster, J., Ordon, F., von Korff, M. and Voll, L. M. 2017. Metabolite profiling of barley flag leaves under drought and combined heat and drought stress reveals metabolite QTLs for metabolites associated with antioxidant defense. J. Exp. Bot. 68:16971713.

Timmusk, S., Abd El-Daim, I. A., Copolovici, L., Tanilas, T., Kännaste, A., Behers, L., Nevo, E., Seisenbaeva, G., Stenström, E. and Niinemets, Ü. 2014. Drought-tolerance of wheat improved by rhizosphere bacteria from harsh environments: Enhanced biomass production and reduced emissions of stress volatiles. PLoS One 9:e96086.

Wang, C.-J., Yang, W., Wang, C., Gu, C., Niu, D.-D., Liu, H.X., Wang, Y.-P. and Guo, J.-H. 2012. Induction of drought tolerance in cucumber plants by a consortium of three plant growth-promoting rhizobacterium strains. PLoS One 7:e52565.

Wang, N., Liu, M., Guo, L., Yang, X. and Qiu, D. 2016. A novel protein elicitor (PeBA1) from Bacillus amyloliquefaciens NC6 induces systemic resistance in tobacco. Int. J. Biol. Sci. 
12:757-767.

Wilson, R. A., Sangha, M. K., Banga, S. S., Atwal, A. K. and Gupta, S. 2014. Heat stress tolerance in relation to oxidative stress and antioxidants in Brassica juncea. J. Environ. Biol. 35:383-387.

Yan, M. 2015. Seed priming stimulate germination and early seedling growth of Chinese cabbage under drought stress. $S$. Afr. J. Bot. 99:88-92.

Yang, Y.-W., Tsai, C.-C., Liou, T.-D. and Chen, K.-S. 2001. Two heat-tolerant F1 hybrids of Chinese cabbage. HortScience 36:1144-1145.

Yang, J., Kloepper, J. W. and Ryu, C.-M. 2009. Rhizosphere bacteria help plants tolerate abiotic stress. Trends Plant Sci. 14:14.

Yoo, S.-J. and Sang, M. K. 2017. Induced systemic tolerance to multiple stresses including biotic and abiotic factors by rhizobacteria. Res. Plant Dis. 23:99-113 (in Korean).

Zandalinas, S. I., Rivero, R. M., Martínez, V., Gómez-Cadenas, A. and Arbona, V. 2016. Tolerance of citrus plants to the combination of high temperatures and drought is associated to the increase in transpiration modulated by a reduction in abscisic acid levels. BMC Plant Biol. 16:105.

Zhao, F., Zhang, D., Zhao, Y., Wang, W., Yang, H., Tai, F., Li, C. and $\mathrm{Hu}, \mathrm{X} .2016$. The difference of physiological and proteomic changes in maize leaves adaptation to drought, heat and combined both stresses. Front. Plant Sci. 7:1471.

Zhou, R., Yu, X., Ottosen, C.-O., Rosenqvist, E., Zhao, L., Wang, Y., Yu, W., Zhao, T. and Wu, Z. 2017. Drought stress had a predominant effect over heat stress on three tomato cultivars subjected to combined stress. BMC Plant Biol. 17:24. 